\section{Fixed ideas take root}

\section{Nodulation in Legumes}

by Janet I. Sprent

Royal Botanical Gardens: 2001. 146 pp. $£ 27$

\section{Sharon R. Long}

The formation of nitrogen-fixing nodules on the roots of legumes (peas, beans and their relatives) is the basis of crop rotation, a mainstay of sustainable agricultural practice. These nodules are the result of an association between the legumes and Rhizobium and allied bacteria. This symbiosis is a wonder of evolution, and has for years been a target for molecular, genetic, physiological and population-level studies.

Many questions have been addressed through the study of model systems of bacteria and legumes. For example, how do bacteria and hosts recognize each other? How do they coordinate action so that the plant produces a completely new organ, the root nodule, which the bacteria invade and inhabit? Why do symbiotic bacteria express their enzymatic apparatus for nitrogen fixation only after developing into specialized forms within the nodule? And why do they fail to assimilate their own fixed nitrogen, instead exporting it to be assimilated by the plant?

And the mystery remains: why legumes? This question refracts into a spectrum of issues related to specificity and adaptation. Why are different legume species or genera nodulated by different (sometimes multiple) bacteria? Why do some legumes appear not to support nodulation? We assume that the plant gains some physiological advantage from the presence of the symbiosis, but how robust is this assumption? Do we know enough about the physiological constraints that limit plant productivity for diverse legumes?

The scope of this second set of questions is as large as the legume family itself (it is the third-largest family of flowering plants) and as wide as the extent of green Earth, for legumes inhabit the tropics and the Arctic, deserts and rainforests, beaches and mountains. Janet Sprent's Nodulation in Legumes is especially valuable because it reminds us that model systems represent only a small part of a big story: how legumes and their rhizobial symbionts work together in the real world.

Early chapters present a concise overview of diversity, physiology and mechanism. Legumes exist in widely varied environments, and their growth maybe subject to varied constraints. During nodule development, bacteria and plant communicate through a set of signals, and new structures and new gene expression characterize both early and late stages of nodulation. The physiology of the nitrogen-fixing state involves careful control of (and often regulation by) the level and the flows of oxygen, nitrogen, carbohydrates or organic acids. These chapters are readable and compact, and do not generally refer to the fastexpanding primary literature on mechanisms of nodulation. Because this research area is dynamic, with conclusions and generalizations constantly being re-examined, students interested in going further should consult more specialized reviews.

A series of further chapters survey nodulation in each of three legume subfamilies: Caesalpinoiodeae, Mimosoideae and Papilionideae. These are especially valuable given the direction in which laboratory science is heading: complete genome-sequencing analyses have recently shown surprising diversity at the whole-genome level of various rhizobia. In parallel, plant genetics and genomics will soon make it possible to look in diverse legumes for symbiosis genes encoding receptors and response pathways. For the next generation of legume researchers, Sprent's book will provide a platform for the expansion of study from a few model systems to a wide world of bacteria and legume hosts.

Questions of evolution and diversity are addressed in the final chapter, using data from the fossil

\section{Winged wonders}

There are over 5,000 known species of dragonfly, and in Dragonflies of the World (Smithsonian Institution Press, \$39.95), Jill Silsby offers a guide to the traits, behaviour and appearance of these insects, crossing the continents to include specimens such as Megalestes kurahashii, shown here, which is found in Thailand.

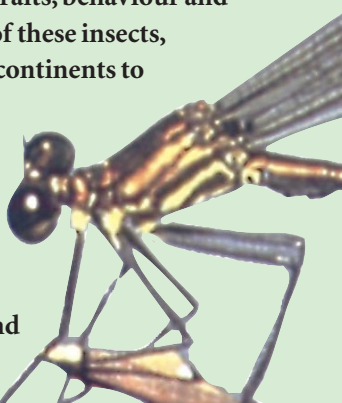

record, morphological analysis and molecular taxonomy, for example. It is extremely valuable to have so much work summarized in one place. Sprent speculates that ancestral legumes had to acquire two features in order to support symbiosis: the suppression of host defences and the pathways to build the nodule structure - a structure that shows considerable variation among members of the family. To these I would suggest a variation: legumes must have the active cellular machinery to support infection, whether or not the plant sustains enough cell divisions to form a nodule. Which prompts me to wonder whether the ancestral events for modern-day nodulation were based in infection, rather than morphogenesis per se, and whether these events might be found in extant legumes that show no visibly evident formation of nodules.

A second printing of the book would provide the opportunity to correct some minor typographical errors that turn up in the table of genera (for example, Daniellia is spelled in two ways, so it looks like two genera in separate parts of the book). But this is a minor issue for a valuable book that Rhizobium-legume researchers and plant-evolution scholars alike should have and should study. As well as reminding us how broad and diverse is the world of symbiosis, and beyond the valuable summaries of physiological and ecological studies, the author conveys a lifetime perspective that places these elements into a framework of knowns and unknowns, of questions central and ancillary. And through it all, every reader of this book will come away feeling the author's love for her subject. The caption to Figure 1.2 begins "Nodule hunting!" That exclamation mark says it all.

Sharon R. Long is in the Department of Biological Sciences, and is dean of the School of Humanities and Sciences, Stanford University, Stanford, California 94305, USA.

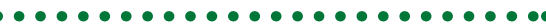 Lightning on the veld}

Schonland: Scientist and Soldier by Brian Austin

Institute of Physics Publishing: 2001. 639 pp.

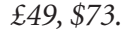

\section{John D. Hey}

The life of Sir Basil Schonland CBE FRS (1896-1972) spanned a crucial period of transition in geopolitical, military and scientific affairs - from the decline of empires to the Cold War and the nuclearbased arms race, and from classical physics to the physics of relativity and the quantum that underpins the technology of the space age. 

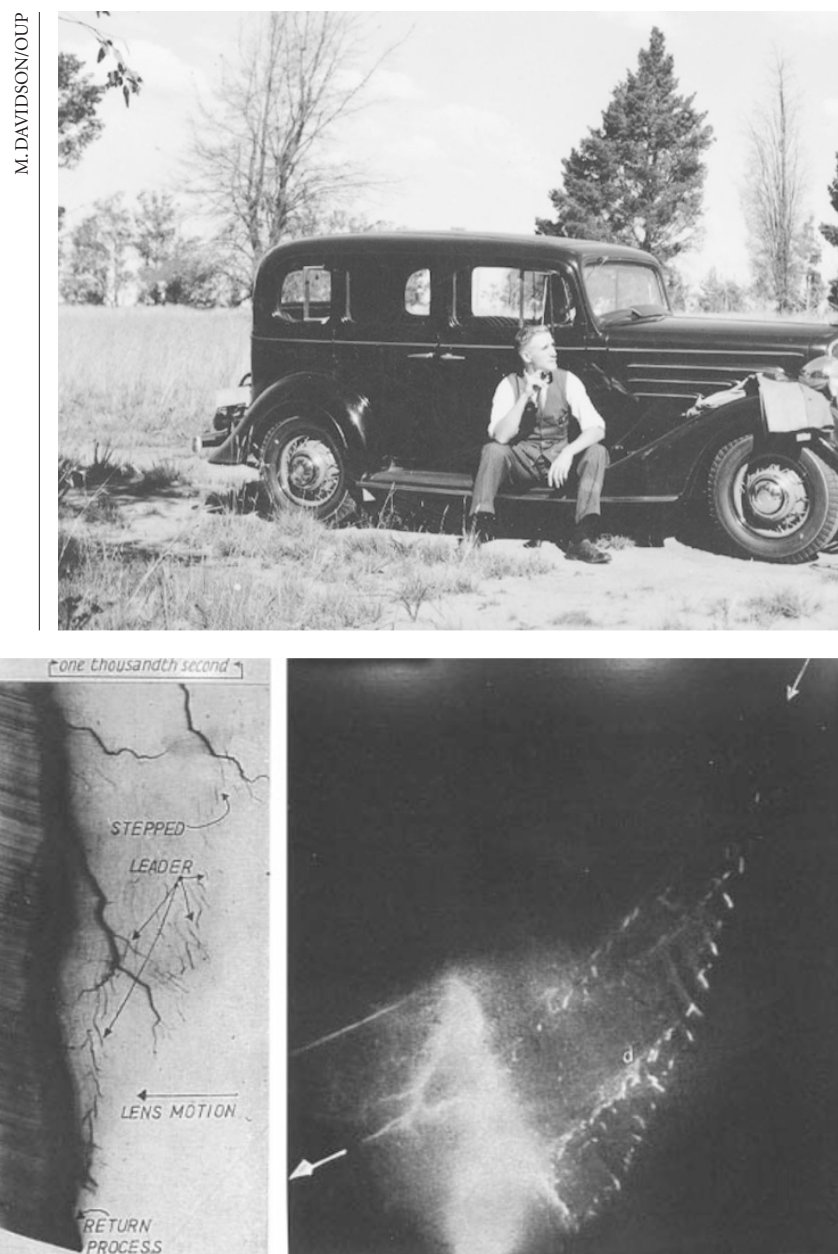

Schonland contributed to both military and scientific developments through a mastery of physics, learned initially in the university town of Grahamstown in the Cape, South Africa, but perfected at the Cavendish Laboratory during the 'golden age' of Sir Ernest Rutherford.

A product of the English type of public school, young Basil's career combined brilliant scholastic triumphs with sturdy character development. He acquired from early youth a belief in the ideals of service to King and Country, and also qualities of leadership, which guided this intellectual brilliance to the benefit of all who later came under his authority.

Austin develops the multi-faceted tale of his achievements in vivid detail. We encounter Schonland as scholar and student, officer and communications specialist in the Royal Engineers, wireless research officer and chief instructor of the British Expeditionary Force, recipient of the OBE (1919), and postgraduate student at Cambridge (1919-1922). Here he grappled with an intriguing scientific puzzle: why the scattering of $\beta$-particles (energetic electrons) by thin metal sheets appeared to contradict the Rutherford atomic model. Meticulous experimental work was supported by the theoretical analysis of Charles G. Darwin.

Awarded his $\mathrm{PhD}$ in 1924, Schonland by impeccable military credentials.

Brian Austin, an expert on research into 'wireless', radio and radar development, succeeds well in covering these aspects of his vast canvas. The text is well referenced and sources include records of interviews with the Schonland family, and former colleagues and students, who themselves played important parts in the story. The book also provides unique insight into the Cavendish at the zenith of the 'old' (Bohr-Sommerfeld) quantum theory. The text and group photographs, including several present and future Nobel laureates, remind us vividly that this period (1919-1928) was a golden age for the Cavendish. Two Nobel laureates (Edward Appleton and Charles Wilson) also played significant roles in Schonland's lightning research, while two others, close contemporaries (Patrick Blackett and John Cockroft), were vitally important to his military activities in the Second World War, to some of his geophysical investigations, to his successful planning and founding of the South African CSIR (1945-1950), and, especially, to his entry (1954) into the troubled fields of nuclear fission and fusion. Contemporary researchers in controlled thermonuclear fusion are provided with a salutary lesson on the dangers of prematurely publicized over-optimism and resource-consuming mammoth experiments, both problems that Schonland encountered in 1958.

The picture of Schonland the man emerges slowly, and is revealed only in the closing pages of the book. Clearly, public service of the highest order, without self-interest, remained pre-eminent throughout, even when the call of duty meant partly sacrificing a promising research career. Thus, ideals acquired in youth remained his lodestone right up to the point at which Schonland, "aged beyond his years", retired from management of the fractious world of large-scale British nuclear science (1954-1961).

Minor blemishes aside, this historical biography is a fine tribute to a legendary and inspiring figure in South African science. It may also serve to inform the reader of different aspects of a country, long under its own thundercloud, and eschewed, even in scientific circles, like the lepers of old - yet, as Thomas Hardy wrote of Egdon Heath, "perfectly accordant with man's nature, but like man, slighted and enduring".

John D. Hey is at the School of Pure and Applied Physics, University of Natal, Durban 4041, South Africa.

Edwin Black Nature published a correction (Nature 415, 370; 2002) citing two errors in a review by Professor Howard Segal of the book IBM and The Holocaust: The Strategic Alliance Between Nazi Germany and America's Most Powerful Corporation by Edwin Black (Nature 411, 993-994; 2001). In addition, Professor Segal, in his review, asserted that the book's author exaggerated the importance of punch-card machines. Nature has been made aware that the reviewer has retracted this assertion, stating: "In fact, I know of no evidence or documentation that the book included any exaggeration at all." 